\title{
A Pioneer Study on a Non-invasive Method for in Ovo Chicken Egg Sexing.
}

\section{Congo Tak Shing Ching}

National Chung Hsing University

\section{Chien-Kai Wang}

National Chung Hsing University

\section{Chin Li}

National Chung Hsing University

Hsuan-Ni Chiu

National Chung Hsing University

Nguyen Van Hieu

Vietnam National University Ho Chi Minh City University of Science: University of Science

Thien Luan Phan ( $\nabla$ phanluan1101@gmail.com )

Vietnam National University Ho Chi Minh City University of Science: University of Science https://orcid.org/0000-0002-5477-0292

\section{Research}

Keywords: Egg sex, Egg gender, Noninvasive, in ovo, Bioimpedance

Posted Date: November 12th, 2021

DOI: https://doi.org/10.21203/rs.3.rs-1047909/v1

License: (c) (i) This work is licensed under a Creative Commons Attribution 4.0 International License.

Read Full License 


\section{Abstract}

Background: Day-old male chicks culling is one of the world most inhumane problems in the poultry industry. Every year, seven billions of male chicks are being killed in laying-hen hatcheries, due to their higher feed exchange rate, lower management compare to female ones and production costs. This work reports a novel non-invasive method for the gender identification of chicken eggs. Four electrodes were attached onto each egg during the incubation process for the data gathering period of fourteen days. Standard polymerase chain reaction (PCR) based chicken gender determination protocol was applied to the eggs on the last day of the incubation process to get the gender information.

Result: A relationship between the collected data and the gender of the egg was built, and it was found to have a reliable connection, indicating that by measure the impedance data of the eggs from day 9 of incubation with the four electrodes setting and applying the self-normalization technique, we can determine the chicken egg gender.

Conclusion: This is a pioneer founding, proving that impedance spectroscopy can be use to sexing of chicken eggs, before its life has been formed, relieving the poultry industry from such an ethical burden.

\section{Introduction}

Due to the different production purposes of the poultry industry, the demand for hatching hens or roosters also varies. In the production of meat and poultry strains, males are only preferred as breeding objects because of their higher feed exchange rate, and lower management and production costs [1]. One of the biggest ethical problems in modern egg-producing poultry farm is culling several billions of day-old male chicks every year. Poultry farms don't rear male domesticated birds because they can neither lay eggs nor put on sufficient flesh for meat production. Globally, it is estimated that 7 billion of day-old male chicks from laying-hen hatcheries are killed annually $[1,2]$.

Traditionally, newly hatched chicks can be identified for genital morphology at the age of one day [3, 4]. Trained and experienced chicken sexers can achieve a success rate of $95 \sim 98 \%$, but it takes two to six years to train and accumulate experience, and there is a lack of sufficient human resources globally for this specific identification work [5]. Also, male and female chicks that are not suitable for production after gender identification need a euthanasia plan as well as chemical treatment equipment. These manpower allocations and processing work have become additional operating costs for the poultry industry, and on the other hand, a major ethical problem in killing lives that have been formed. At the moment, animal welfare issues has become increasingly important in developing countries. For example, EU legislation has facilitated market segmentation through trade standards for eggs (enriched cages, floor system, and free-range) and standardization of organic livestock production. Industries may introduce higher animal welfare standards for the goal of developing a national profile. Examples are Danish, and German egg production, which have committed to stop the beak trimming of layers [6]. EU has also discussed whether law enforcement should be used to restrict the poultry industries from continuing to adopt the gender 
elimination strategy. But without a proper fully pledged technology to determine the chick sex before its life's been formed, the law has not been able to restrict industries from doing what they have been doing for decades.

At the beginning of 2018, a study from the University of Leipzig [7] has stated that Fluorescence and Raman spectroscopy of blood offers the potential for precise and contact less in ovo sex determination of the chicken eggs during the fourth incubation day. Although this is a very fast and precise method, only 3.5 days of incubation process and the accuracy is said to be above $90 \%$ [7], such kind of spectroscopy requires a window on the eggshell (Figure 1), meaning this is an invasive method and will affects the embryo, which leads to decrease in hatching rates.

Many other researches such as German's Agri Advance Technoligies, French's Tronico (funded by the government in 2017), and Canadian's Hypereye (started in 2007, refunded by the government in 2018) [810] has been made based on the spectroscopy method but there are no results have been reported even though most of them promised to deliver the technology in $2019-2020$ period.

It was not until the late end of 2018, the first fertilized egg's gender detection technology has been introduced to the commercial production of laying hens, the Seleggt method. This technology is derived from another detection technology also developed by the University of Leipzig, Germany. On the blunt end, the eggshells were cut open using laser after 8 to 10 days, estimated time when the hormone can be found in the egg [11-14], of incubating, then a small amount of egg content solution was extracted and are used to measure the Estrogen content. Since the amount of estrone sulfate in the female embryos is significantly higher than that in males at the time hormone has already presented in the egg, it can be used as a basis for identification [11-14]. Although comparing to the manual identification methods this method is considered to have the same identification rate, due to the eggshell perforation sampling work, higher sanitary conditions are required for subsequent incubation facilities and environments to avoid possible pollution and incubation losses. Also, this commercial technology currently using radioimmunoassay for the determination of estrin, so relative technical cost and analysis time are not easy to reduce and shorten. In other words, the current commercialized technology still needs to complete the gender identification process through intrusive sampling and biochemical analysis. The direction of future technology development is to replacing intrusion sampling with non-invasive methods and fast real-time analysis, photoelectric analysis equipment is an example.

Impedance spectroscopy is a proven method for many applications such as bacterial detection, biomarker detection, microorganism viability determination [15-20]. The principle of this technique is to inject a constant into the object to be measured and calculate its voltage to find out the electrical impedance respond of the object. Based on a study by Burke and Sharp in 1989, compared to hens, the eggs that hatched into roosters have larger yolks [13], it is reasonable to believe that these eggs will have different electrical impedance value. As the eggshell can be imagined as the cell membrane, the protein can be imagined as the cytoplasm, and the egg yolk can be imagined as the nucleus, the theory of impedance spectroscopy can be logically apply for this case. 
This work present the development process of a method for non-invasive in ovo chicken eggs gender identification applying the impedance spectroscopy technique. The gender will be confirmed after the incubation process by using standard PCR chicken egg gender identification process. The presented work involve an integrated system of measuring electrodes and incubation machine, which will be a great access for future development of a commercially available technology in non-invasive chicken egg sexing of poultry industry, solving a huge ethical problem globally, where billions of one-day old male chick are being culled annually. The main contributions of this research are as follows:

1. Design and implementation of a simple and effective electrode for measuring egg impedance in incubation environment.

2. Relationship development between chicken egg impedance and its gender

3. Integration of the electrode system and the chicken egg incubation machine, proving the possibility of future development for a fully integrated system to non-invasive sexing method.

\section{Materials And Methods}

\section{Eggs and chemical preparation}

Fertilized Kinman county, Taiwan, chicken eggs were obtained from Department of Animal Science, National Chung Hsing University.

Potassium permanganante $\left(\mathrm{KMnO}_{4}=158.04\right)$ and Formalin $(\mathrm{HCHO}=30.02)$ extra pure reagent was purchased from Choneye Pure Chemical (Taiwan). Blood Genomic DNA purification kit for PCR gender identification were purchased from Biokit (Barcelona, Spain)

\section{Carbon epoxy based electrode}

Electrode performance are very important in impedance spectroscopy technique. The electrode should be low noise, repeatable, and accuracy. For the development process, standard ECG electrode was used for evaluation step.

Approximately 40 cubic millimeters $\left(\mathrm{mm}^{3}\right.$ ) of carbon epoxy (volume resistivity of $\approx 400 \mathrm{hms} \cdot \mathrm{cm}$ ) was dropped onto a $10 \times 10(\mathrm{~mm})$ adhesive conductive cloth (contact resistance of $0.050 \mathrm{hms} / \mathrm{cm} 2)$ (Figure 2a) where the cloth will be used to stick on one end of the RG-1.13m coaxial cable (Figure $2 \mathrm{c}$ ) to the designated point on the chicken egg. The designated points on the eggs will be discussed in the later part of this paper. Using the resistivity forrmula $\rho=R * A / l$, where $\mathrm{R}$ is the resistance, $\mathrm{A}$ is the crosssectional area, and $I$ is the length of the specimen, plus the resistance of the $1 \mathrm{~cm}^{2}$ conductive cloth piece, the total resistance of the electrode was calculated to be $2.05 \mathrm{Ohm}$.

\section{Chicken egg electrodes positions}

While putting in the incubator, the blunt end of the egg should face upward as seen in Figure 3 . In this experiment, we wants to measure the eggs impedance at differents positions. For this pioneer study, we 
chose to put the electrode as shown in Figure 3, based on the standard body mass bio-electrical impedance analysis. An electrode will be attached onto both blunt and pointy ends of the egg marking position 1 and 2 (on the height circuference), whereas position 3 and 4 are determined by marking the width circumference of the egg where position 3 is a random point on the circumference and position 4 is opposite to position 3 .

\section{Pinout circuit}

The coaxial cables after being attached on to the eggs at one end were connected to a pinout circuit (Figure 4) at the other end using SMA headers (U1 - U4) making it easier for data acquisition process. The purpose of the pinout circuit is firstly to make it easier to switch between electrodes during measurements, secondly shielding to reduce the noise causes by electrostatic of a large number of wires. The Impedance Analyzers probes will be attached onto the $\mathrm{C} 1$ and $\mathrm{C} 2$ pins.

\section{Experimental setup}

The obtained were put inside the incubator for 14 days in total, from day 0 to day 13 of incubation process. During this incubation period, measurements were made with the eggs are still inside the incubator by attaching the Impedance Analyzer (WK6420) probes to the pinout circuits.

\subsection{Incubator preparation}

DI water was stored in a 10 liters tank and were used by the incubator to maintain the humidity during the incubation process, this DI water must be refilled when needed. The humidity level was kept stable at 54$56 \%$ and the temperature was $99.5^{\circ} \mathrm{F}$ (Figure $6 \mathrm{c}$ ). Before this incubation process, sterilization of the incubation area must be performed. Standard fumigation process was applied to sterilize the incubator before each incubation process.

The sterilization process consists of steps described as below:

a. Clean the inside of the incubator thoroughly using clean towel

b. Seal all of the air holes on the incubator, making sure no air leakage can happen

c. Exact $3 \mathrm{mg}$ of potassium permangannate was spooned into a ceramic container

d. Put the ceramic container inside the incubator through the main door

e. Exact $6 \mathrm{ml}$ of formalin was pipetted into the container

g. Immediately closed the door, and tightly sealed it as chemical reaction happen inside, where a poisonous brown-purple formaldehyde gas being produced. 
h. After 20 minutes, the vent and other air holes of the incubator can be opened for air circulation.

Remove the ceramic container and the incubator is sanitized.

\subsection{Bioimpedance measurement experiment design}

Bioimpedance data were measured using the Wayne Kerr 6420C Impedance Analyzer \& LCR Meter (Wayne Kerr Electronics, USA) (Figure 5). The parameters are set as :

- $100 \mathrm{mV}$ rms voltage

- Frequency range of $20 \mathrm{~Hz}$ to $10 \mathrm{MHz}$ (100 points)

- Measurement speeds of $80 \mathrm{~ms}$ per measurement

On the day of collection, fertilized eggs were stored at room temperature for electrode attachments. After the carbon epoxy based electrodes has been firmly attached onto the eggs it was let cure in room temperature for 24 hours before being put inside the incubator. A small hole with a diameter of $20 \mathrm{~mm}$ was drilled out as can be seen in figure $6 \mathrm{a}, \mathrm{b}$. then by inserting a $20 \mathrm{~mm}$ PVC tube into the hole, the cable were tunneled out. This tube was tightly sealed during the incubation process.

The impedance measurement experiment was performed step-by-step as described below:

a. Unsoiled the surface of the egg using a dry and clean towel, and marked using pencil. The eggs are kept at room temperature.

b. $10 \mathrm{~mm} \star 10 \mathrm{~mm}$ pieces of conductive fabric cloth were cut out and measured.

c. 1 meter long coaxial cables was cut, striped and shield layer insulated with heat-shrunk tubing.

d. $40 \mathrm{~mm}^{3}$ of carbon epoxy was dropped onto the conductive fabric cloth.

e. Put the stripped end of the coaxial cable into the carbon epoxy dropped conductive fabric cloth.

f. Tape the whole configuration onto desired positions of each egg.

g. Let cured at room temperature for 24 hours.

h. Put the eggs inside the incubator, tunneled the wires out and connect them to SMA heads and pinout circuit.

Every another 24 hours, make the impedance spectrum measurement for 13 more days

\subsection{Genomic DNA extraction and gender identification using PCR}

A standard PCR process described in [27], where genimoc DNA of the chick was collected from its blood and applied to the PCR, was used to determined the gender of the chicken egg after day 13 of incubation. The genomic DNA collection process is as followed: 
a. A $10 \mu \mathrm{L}$ whole blood sample was collected from each chicken fetus after 14 days (from day 0 to day 13) incubation. The whole blood sample contained le.ukocytes and provided genomic DNA for gender identification. Genomic DNA was extracted using Blood Genomic DNA purification kti (Biokit, Barcelona, Spain).

b. The whole blood sample was added with $20 \mu \mathrm{L}$ proteinase $\mathrm{K}, 170 \mu \mathrm{L}$ Phosphate buffered solution and $200 \mu \mathrm{L}$ binding buffer together.

c. The mixture was then vortexed and incubated in $70^{\circ} \mathrm{C}$ oven overnight.

d. After overnight incubation, each mixed sample was added with $200 \mu \mathrm{L} 100 \%$ ethanol and transferred into filter column provided by Biokit genomic DNA purification kit.

e. This filter column was then centrifuged at $15,000 \times \mathrm{g}$ for $1 \mathrm{~min}$ in room temperature.

f. The suspend solution was discarded, and pellet was washed with $600 \mu \mathrm{L}$ washing buffer followed $15,000 \times \mathrm{g}$ centrifuge for $1 \mathrm{~min}$ in room temperature, twice.

g. Centrifuged again at $15,000 \times \mathrm{g}$ for $3 \mathrm{~min}$ in room temperature to remove remained water.

h. A $1.5 \mathrm{~mL}$ microtube was inserted with the filter column and $25 \mu \mathrm{L}$ elution buffer was added into filter column to collect isolated genomic DNA.

Table 1

PCR program for chicken gender identification.

\begin{tabular}{|llll|}
\hline & \multicolumn{2}{l|}{ Temperature } & Time \\
\hline Initial & $95^{\circ} \mathrm{C}$ & $30 \mathrm{~s}$ & \\
\cline { 1 - 3 } Denaturation & $95^{\circ} \mathrm{C}$ & $30 \mathrm{~s}$ & $30 \mathrm{cycle}$ \\
\cline { 1 - 2 } Annealing & $58^{\circ} \mathrm{C}$ & $1 \mathrm{~min}$ & \\
\cline { 1 - 2 } Extension & $72^{\circ} \mathrm{C}$ & $1 \mathrm{~min}$ & \\
\hline Finish & $72^{\circ} \mathrm{C}$ & $5 \mathrm{~min}$ & \\
\hline
\end{tabular}

PCR was performed as Table 1. with each sample containing a total $25 \mu \mathrm{L}$ mixture of $2 \mu \mathrm{L}$ eluted genomic DNA, $16 \mu \mathrm{L}$ deionized water, $5 \mu \mathrm{L}$ master mix, $1 \mu \mathrm{L} 2250$ forward primer (5'GTTACTGATTCGTCTACGAGA-3'), and $1 \mu \mathrm{L} 2718$ reverse primer (5'-

ATTGAAATGATCCAGTGCTTG-3') using Biometra T-Personal thermal cycler (Analytikjena $\mathrm{GmBH}$, Jena, Germany). The primer design is based on a pilot study for gender identification on avian (Romanova et al., 2019). Agarose gel (2\%) electrophoresis was performed to analyze PCR products. Single band of $552 \mathrm{bp}$ indicated a male fetus, whereas double bands in $358 \mathrm{bp}$ and $552 \mathrm{bp}$ indicated a female fetus (Figure 7).

6. Statistical analysis 
Independent T-test statistical analysis using Microsoft Excel were made in order to construct the relationship between the chicken egg sex and the collected impedance data.

\section{Results And Discussion}

\section{Electrode Evaluation Test}

To validate the elctrode performance it was tested with two different test. The first one is to measure the resistance of the electrodes making sure that they are similar, reducing electrode impedance error. The second test involve using an unfertilized, unhatchable egg. By measuring its impedance spectrum over a span of eleven days in and outside of the incubation, the performance of the electrode can be validated.

A total of 20 electrodes configuration was prepared without taping onto the egg. Their resistance was measured using a standard Fluke multimeter. As shown in Figure 8, the measured resistance was found varies from 1.78 to 3.12 with an average of 2.383. This was found to be in agreement with the calculated resistance value of the electrodes mentioned in the carbon epoxy electrode fabrication above.

An unhatchable egg was attached with a pair of ECG electrode on the blunt and pointy ends of the egg, impedance measurement was made then remove the ECG electrode. After the ECG electrodes was removed, and its surface has been wiped clean with a dry towel, a pair of designed electrode was attached to position 1 and 2 of the egg. The impedance spectrum was made after 24 hours of attachment at room temperature. Then again after 1 hour it has been put in the incubator at a temperature of 99.5 Fahrenheit degree, this was marked as Day 0 of incubation measurement. Then the impedance was measured again on Day 1, 4, and Day 10 of the incubation process, these measurement was made to test the electrode performance after a long time in a fixed humidity (55\%) and temperature $\left(99.5^{\circ} \mathrm{F}\right)$ environment. The impedance spectrum is shows in figure 9 , from here, it can be observed that there is variation in impedance value at very low frequencies $(20 \mathrm{~Hz}$ to $100 \mathrm{~Hz})$. But from the frequency of $100 \mathrm{~Hz}$ and above, the agreement level is acceptable at below $5 \%$ error.

2. Chicken egg gender evaluation test

\subsection{PCR chicken egg sex result}

Among the 27 Kinmen county fertilized eggs obtained from Department of Animal Science, (National Chung Hsing Uniersity, Taichung, Taiwan) 1 were none fertilized, 13 were male, and 14 were female. Table 2 summarize the result of the PCR chick egg sex determination. 
Table 2

Survival and gender records for 14 days incubating fetal Kinmen county chicken

\begin{tabular}{|c|c|c|c|}
\hline No. & Status & Survival status at gender identification day & Gender \\
\hline 1 & + & Good & M \\
\hline 2 & + & Good & M \\
\hline 3 & + & Good & M \\
\hline 4 & + & Good & $\mathrm{F}$ \\
\hline 5 & + & Good & M \\
\hline 6 & + & Good & $\mathrm{F}$ \\
\hline 7 & + & Good & $\mathrm{F}$ \\
\hline 8 & + & Good & $\mathrm{F}$ \\
\hline 9 & + & Good & M \\
\hline 10 & + & Good & $\mathrm{F}$ \\
\hline 11 & + & Good & $\mathrm{F}$ \\
\hline 12 & + & Good & $M$ \\
\hline 13 & + & Good & $M$ \\
\hline 14 & + & Good & $F$ \\
\hline 15 & $\mathrm{~N} / \mathrm{A}$ & - & - \\
\hline 16 & + & Good & $M$ \\
\hline 17 & + & Good & $F$ \\
\hline 18 & + & Good & $\mathrm{F}$ \\
\hline 19 & + & Good & $\mathrm{F}$ \\
\hline 20 & + & Good & $\mathrm{F}$ \\
\hline 21 & + & Good & $M$ \\
\hline 22 & + & Good & $\mathrm{F}$ \\
\hline 23 & + & Good & $\mathrm{F}$ \\
\hline 24 & + & Good & $M$ \\
\hline 25 & + & Good & $M$ \\
\hline 26 & + & Good & $F$ \\
\hline \multicolumn{4}{|c|}{ Remarks: N/A: none fertilized or dead with fetal condition, +: Fertilized, M: Male, F: Fema } \\
\hline
\end{tabular}




\begin{tabular}{|llll|}
\hline No. & Status & Survival status at gender identification day & Gender \\
\hline 27 & + & Good & M \\
\hline Remarks: N/A: none fertilized or dead with fetal condition, +: Fertilized, M: Male, F: Female \\
\hline
\end{tabular}

\subsubsection{Impedance spemtrum result data}

Due to the noises found in the spectrum, self-normalization idea, which was used in Phan et al (2021) [28], has been utilized in studying the parameter, with the intention of keeping away the large embryos-toembryos differences during data analysis. This ratio data would shows more independent and reliable on distinguished the gender differences. The result is shown in Figure 12. And as observed, inspite of the large variations in the low frequencies zone $(20 \mathrm{~Hz}-100 \mathrm{kHz})$, at high frequencies, characteristic curves was found. At this frequency range of $300 \mathrm{kHz}$ to $10 \mathrm{MHz}$, for either male or female, the ratio between impedance value of the eggs shows a noticeable steadiness. To visualize this changes, mean value of male eggs and female eggs were calculated, and were scattered with days data at different frequency. By doing this, we would be able to find the frequency at which the gender of the egg can be distinguished by comparing the ratio value between position 2-3 and position 2-4.

From observing the spectrum, it is noticeable that for male eggs, the ratio data in the frequency range of $300 \mathrm{kHz}$ up to $10 \mathrm{MHz}$ has a value of larger than 1, while for female eggs, this ratio value is almost alway falls below 1 . But to prove that the different can be use to correctly distinguished the gender of the egg, statistical method must by apply.

From statistical independant $T$ test, the ratio of impedance measurements between position 2-3 and 2-4 shows significant relationship with the chicken egg gender. Figure 13 shows the mean ratio value spectrum of male and female eggs measured at day 9 , in the optimum frequency range of $376 \mathrm{kHz}$ to $2.69 \mathrm{MHz}$. Among this range, the measurement of male and female eggs shown significant different with $p$ value of independant T-test lowest at 0.02 at the frequency of $376 \mathrm{kHz}$. Moreover, the significant different found at this range on day 9 was also found on others incubation days until the end of the incubation process, on day 13.

Figure 14 shows that the impedance ratio value of male and female eggs has always show a certain level of distinction. But it was not until day 9 of incubation that this difference become significant (confirmed by independant T-test). From then until the last day of experiment, the difference has always been significant. This is believe to be due to different in embryos weight of male and female egg.

Burke and Sharp study [13] has proved a phenomenon, by cracking the eggshell and weigh the wet and dry embryos weight, Burke and Sharp stated in their studies that they have found a different in embryos weight of male and female eggs at very early of incubation but the different only become significant from day 11 of incubation process. And from experiment result, this study believes to have found the significant, in ovo, from day 9 of incubation, with bio-electrical impedance analysis have always been able to acccurately analize human body composition. 


\section{Conclusion}

A pinoeer study has been made on a non invasive method for chicken egg gender identification. The result indicates that this is a promising humane method for mass egg production poultry industries. By measuring the impedance of fertilized chicken eggs during day 9 of incubation, between pair 2-3 and 2-4 at $376 \mathrm{kHz}$, the gender of the eggs can be distinguished. Future studies on electrode optimization should be made for electrode positions, electrode material, and electrode impedance stabilization. A larger pool of sample is also in consideration to increase the accuracy of the method.

\section{Declarations}

\section{Ethics approval and consent to participate}

Experiments conducted on chicken eggs were approved by National Chung Hsing University, Taichung, Taiwan.

\section{Consent for publication}

The manuscript does not contain data from any individual person.

\section{Availabitility of data and material}

Raw data were generated at Graduate Institute of Biomedical Engineering, College of Engineer, National Chung Hsing University, Taichung, Taiwan. Derived data supporting the findings of this study are available from the corresponding author Thien Luan Phan on request.

\section{Competing interests}

No potential competing interest was reported by the authors.

\section{Funding}

This work was supported by grant (109-2313-B-005 -007 -) from the Ministry of Science and Technology, Taiwan, Republic of China.

\section{Author's contributions}

Congo Tak Shing Ching: Research conception and design; Funding acquisition; Data validation; Manuscript editing. Chien-Kai Wang: Data validation; Manuscript editing. Chin Li: Data collection. HsuanNi Chiu: Data collection. Nguyen Van Hieu: Data validation; Manuscript editing. Thien Luan Phan: Data collection and analysis; Manuscript writing. All authors read and approved the final manuscript.

\section{Acknowledgments}

All authors declare that there isn't anyone other than the authors to acknowledge. 


\section{References}

1. M-E Krautwald-Junghanns, K Cramer, B Fischer, A Förster, R Galli, F Kremer, E U Mapesa, S Meissner, R Preisinger, G Preusse, C Schnabel, G Steiner, T Bartels, Current approaches to avoid the culling of day-old male chicks in the layer industry, with special reference to spectroscopic methods, Poultry Science, Volume 97, Issue 3, March 2018, Pages 749-757, https://doi.org/10.3382/ps/pex389.

2. David Reid. Germany hopes new technology will stop the slaughter of male chicks. CNBC Food \& Beverage, Thu, May 302019

3. Robinson Bosk, Beth. "Sexing Day-Old Chicks: How to Identify Pullets and Cockerels". motherearthnews.com. Retrieved 30 August 2015.

4. Lloyd, Prof. E.A. "Sexing Baby Chicks". AG Annex. Retrieved 30 August 2015.

5. Göhler, Doreen; Fischer, Björn; Meissner, Sven (2017). "In-ovo sexing of 14-day-old chicken embryos by pattern analysis in hyperspectral images (VIS/NIR spectra): A non-destructive method for layer lines with gender-specific down feather color". Poultry Science. 96 (1): 1-4. doi:10.3382/ps/pew282. PMID 27591278.

6. Jan Tind Sørensen, Lars Schrader. Labelling as a Tool for Improving Animal Welfare - The Pig Case. Agriculture 2019, 9(6),123.

7. Roberta Galli, Grit Preusse, Christian Schnabel, Thomas Bartels, Kerstin Cramer, Maria-Elisabeth Krautwald-Junghanns, Edmund Koch, Gerald Steiner. Sexing of chicken eggs by fluorescence and Raman spectroscopy through the shell membrane. PLoS ONE 13(2): e0192554.

8. https:// (Visited Nov 4th 2021)

9. https:// (Visited Nov 4th 2021)

10. Phelps P, Bhutada A, Bryan S, Chalker A, Ferrell B, Neuman S, et al. Automated identification of male layer chicks prior to hatch. Worlds Poult Sci J. 2003 Mar; 59(1): 33-8.

11. Tran HT, Ferrell W, Butt TR. An estrogen sensor for poultry sex sorting. J Anim Sci. 2010 Apr; 88(4): 1358-64. https://doi.org/10.2527/jas.2009-2212 PMID: 20081077.

12. Weissmann A, Reitemeier S, Hahn A, Gottschalk J, Einspanier A. Sexing domestic chicken before hatch: A new method for in ovo gender identification. Theriogenology. 2013 Aug; 80(3): 199-205. https://doi.org/10.1016/j.theriogenology.2013.04.014 PMID: 23726296.

13. Burke, W. H.; Sharp, P. J., Sex differences in body weight of chicken embryos. Poultry science 1989, 68 (6), 805-10.

14. Sun, T.P.; Ching, C.T.; Cheng, C.S.; et al., The use of bioimpedance in the detection/screening of tongue cancer. Cancer Epidemiol. 2010, 34 (2), 207-211.

15. Phan TL, Hieu NV, Li TS, Tsao KC, Ching CTS. Noninvasive and real-time in vivo characterization of Inflammation skin. A feasibility of animal study. Skin Res Technol. 2021 Sep;27(5):846-853.

16. Yang, W.-C.; Liao, S.-Y.; Phan, T.L.; Van Hieu, N.; Chu, P.-Y.; Yi, C.-C.; Wu, H.-J.; Chang, K.-M.; Ching, C.T.S. An Immunosensor for the Detection of ULBP2 Biomarker. Micromachines 2020, 11, 568. 
17. Xu M, Wang R, Li Y. Rapid detection of Escherichia coli 0157:H7 and Salmonella Typhimurium in foods using an electrochemical immunosensor based on screen-printed interdigitated microelectrode and immunomagnetic separation. Talanta. 2016;148:200-8. doi: 10.1016/j.talanta.2015.10.082. Epub 2015 Oct 28. PMID: 26653441.

18. Sheng-Yang Huang, Chia-Man Chou, Tsung-Han Chen, Pei-Chuen Chiou, Vincent K. S. Hsiao, Congo Tak-Shing Ching and Tai-Ping Sun. Enhanced Sensitivity Using Microfluidic, Interdigitated Microelectrode Based Capacitance Glucose Sensor Measured at $4 \mathrm{MHz}$. Journal of the Electrochemical Society 2014; 161: B102-B105

19. Congo Tak-Shing Ching*, Nguyen van Hieu, Teng-Yun Cheng, Lin-Shien Fu, Tai-Ping Sun, Ming-Yen Liu, Su-Hua Huang* and Yan-Dong Yao. Liver Cancer Detection by a Simple, Inexpensive and Effective Immunosensor with Zinc Oxide Nanoparticles. Sensors 2015; 15: 29408-29418

20. Sun, T.P.; Ching, C.T.; Cheng, C.S.; et al., The use of bioimpedance in the detection/screening of tongue cancer. Cancer Epidemiol. 2010, 34 (2), 207-211.

21. Amraee, T.; Ranjbar, S., Transient instability prediction using decision tree technique. IEEE Tran. On Power Systems 2013, 28(3), 3028-3037.

22. Liu, W.; Wang, Z.; Liu, X.; Zeng, N.; Liu, Y.; Alsaadi, F. E., A survey of deep neural network architectures and their applications. Neurocomputing, 2017, 234, 11-26.

23. Vanneschi, L.; Castelli, M., Multilayer Perceptrons. In Encyclopedia of Bioinformatics and Computational Biology, 2018, 1, 612-620.

24. Romanoff, A. L., 1936. Effects of different temperatures in the incubator on the prenatal and postnatal development of the chick. Poultry Sci. 15:311-315.

25. Romanoff, A. L., 1939. Effect of temperature shock on development of chick embryo. Pages 184186 in Proc. 7th World's Poultry Congr.

26. Romanoff, A. L., 1960. The avian embryo. The Macmillian Co., New York, NY.

27. Romanoff, A. L., 1967. Biochemistry of the avian embryo. John Wiley and Sons, New York, NY.

28. Romanoff, A. L., L. L. Smith, and R. A. Sullivan, 1938. Biochemistry and biophysics of the developing hen's eggs. III. Influence of temperature. Cornell Univ. Agr. Exp. Sta. Memoir 216.

29. Romanova, M. N., A. M. Betuelb, L. G. Chemnickc, O. A. Ryderc, R. O. Kulibabad, O. V. Tereshchenkoe, W. S. Paynef, Ph. C. Delektaf, J. B. Dodgsonf, E. M. Tuttleb, and R. A. Gonserb. 2019. Widely Applicable PCR Markers for Sex Identification in Birds. Russian Jour. Gen. 55:220-231.

30. Phan, TL, Hieu, NV, Li, TS, Tsao, K-C, Ching, CTS. Noninvasive and real-time in vivo characterization of Inflammation skin. A feasibility of animal study. Skin Res Technol. 2021;00: 1-8.

\section{Figures}




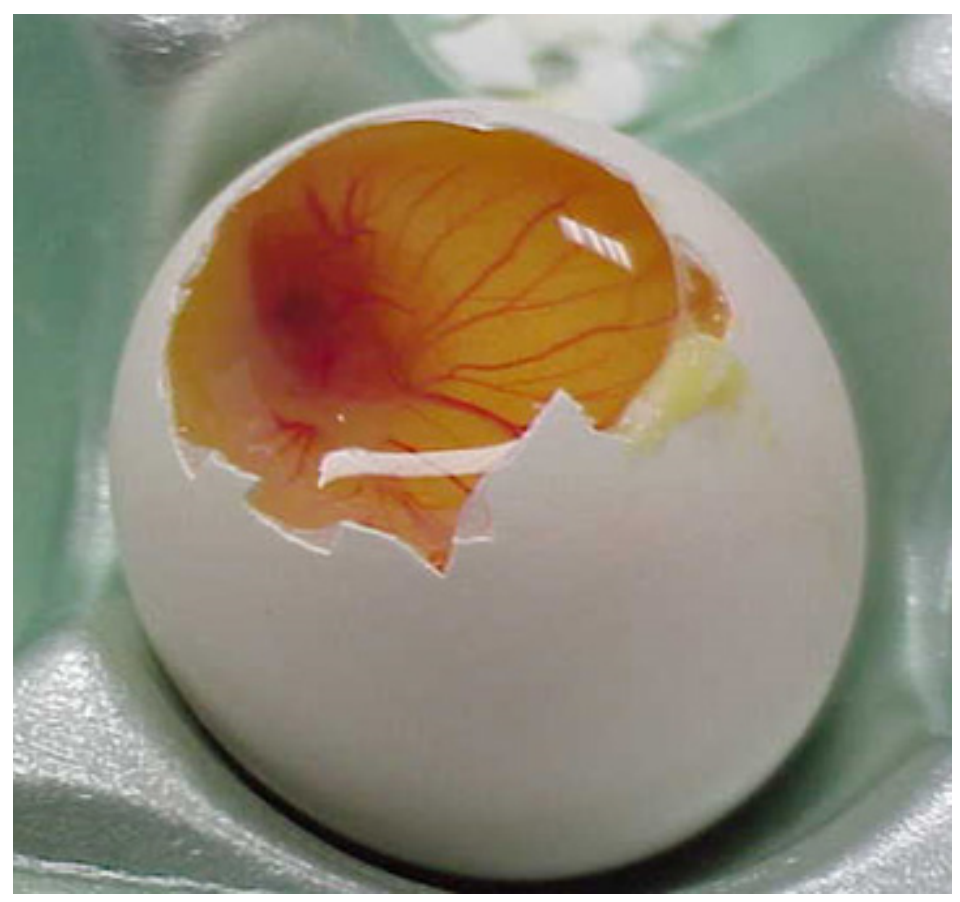

\section{Figure 1}

Vascular vessels of an egg which embryos is at day 5 of incubation with the blunt end has been cut open. 展

\section{Figure 2}

(a) Carbon epoxy was dropped onto $10 \mathrm{~mm} \times 10 \mathrm{~mm}$ adhesive conductive cloth (b) taped onto designated points on a chicken egg using (c) RG-1.13mm coaxial cable 


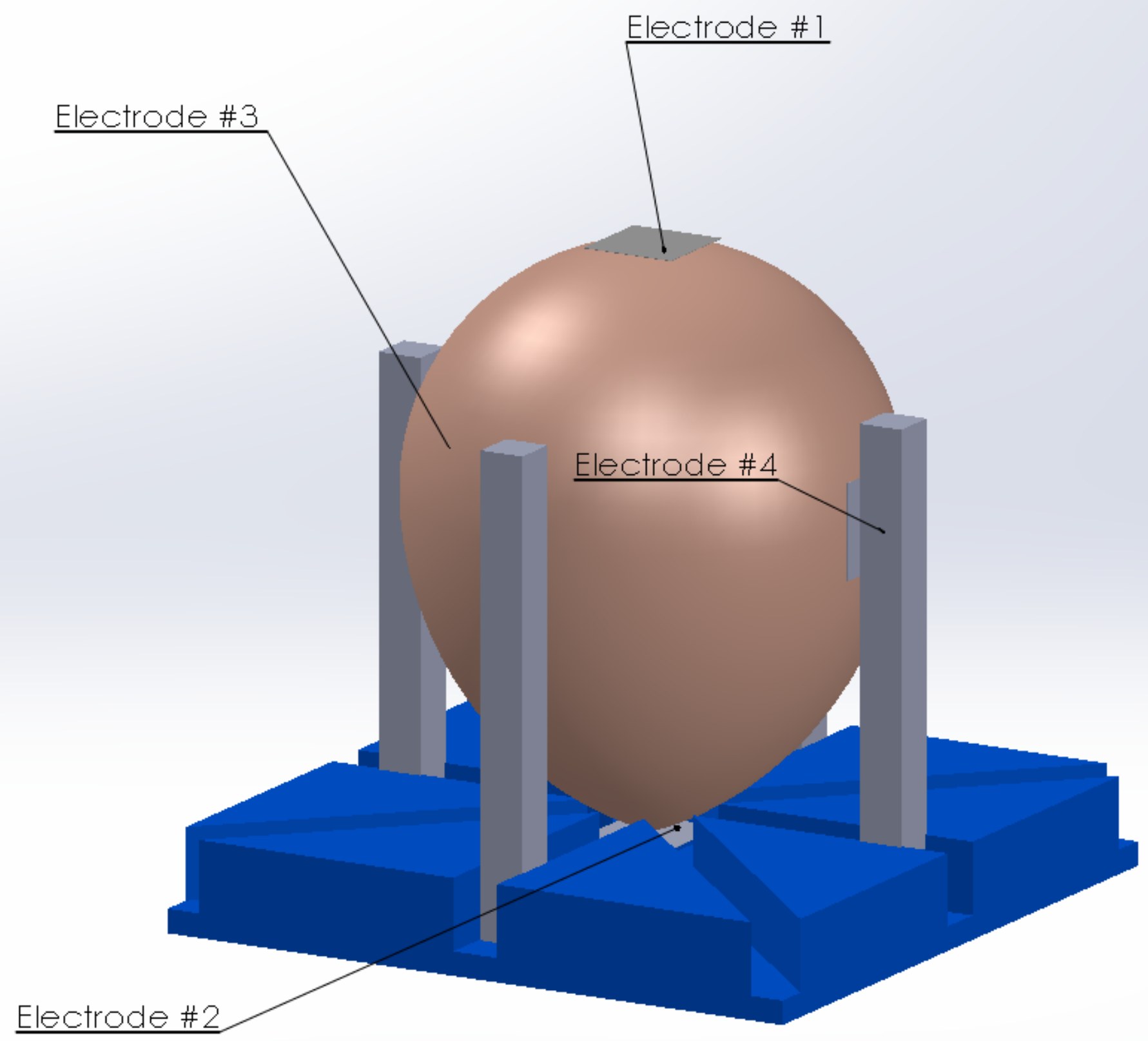

Figure 3

Demonstation of the designed device to determine the electrodes positions 


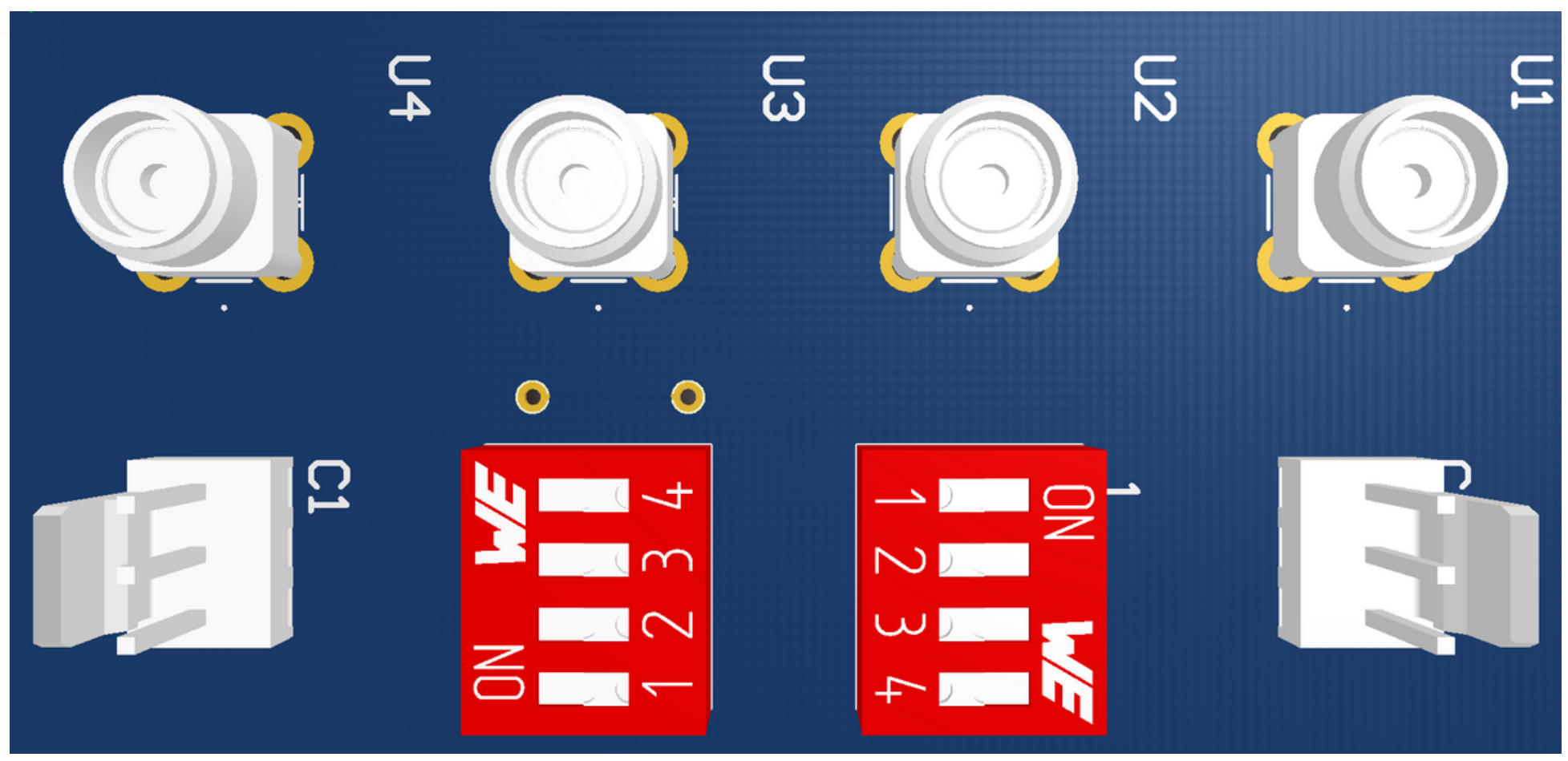

Figure 4

The pinout circuit 


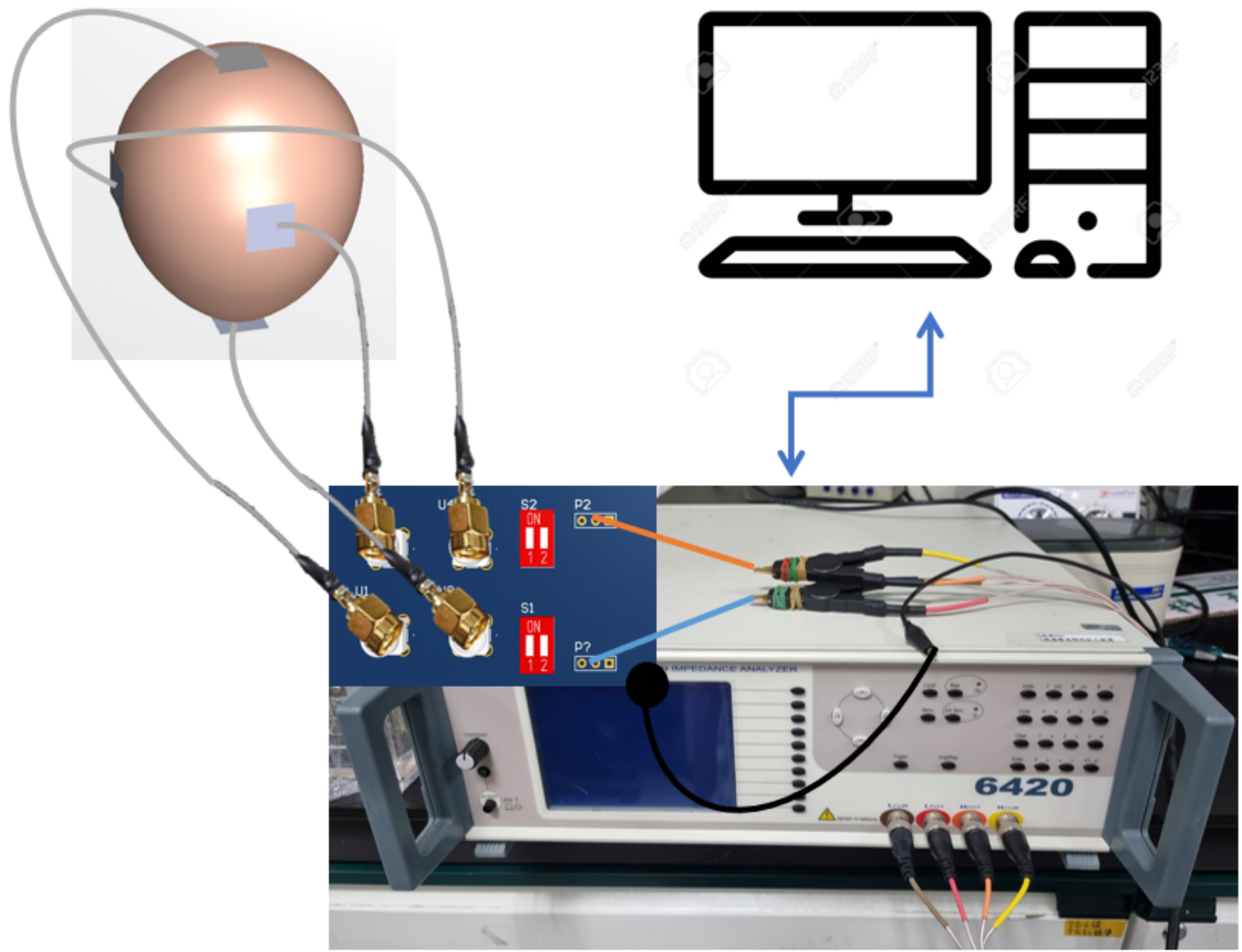

Figure 5

Experimental setup for egg bioimpedance measurement 


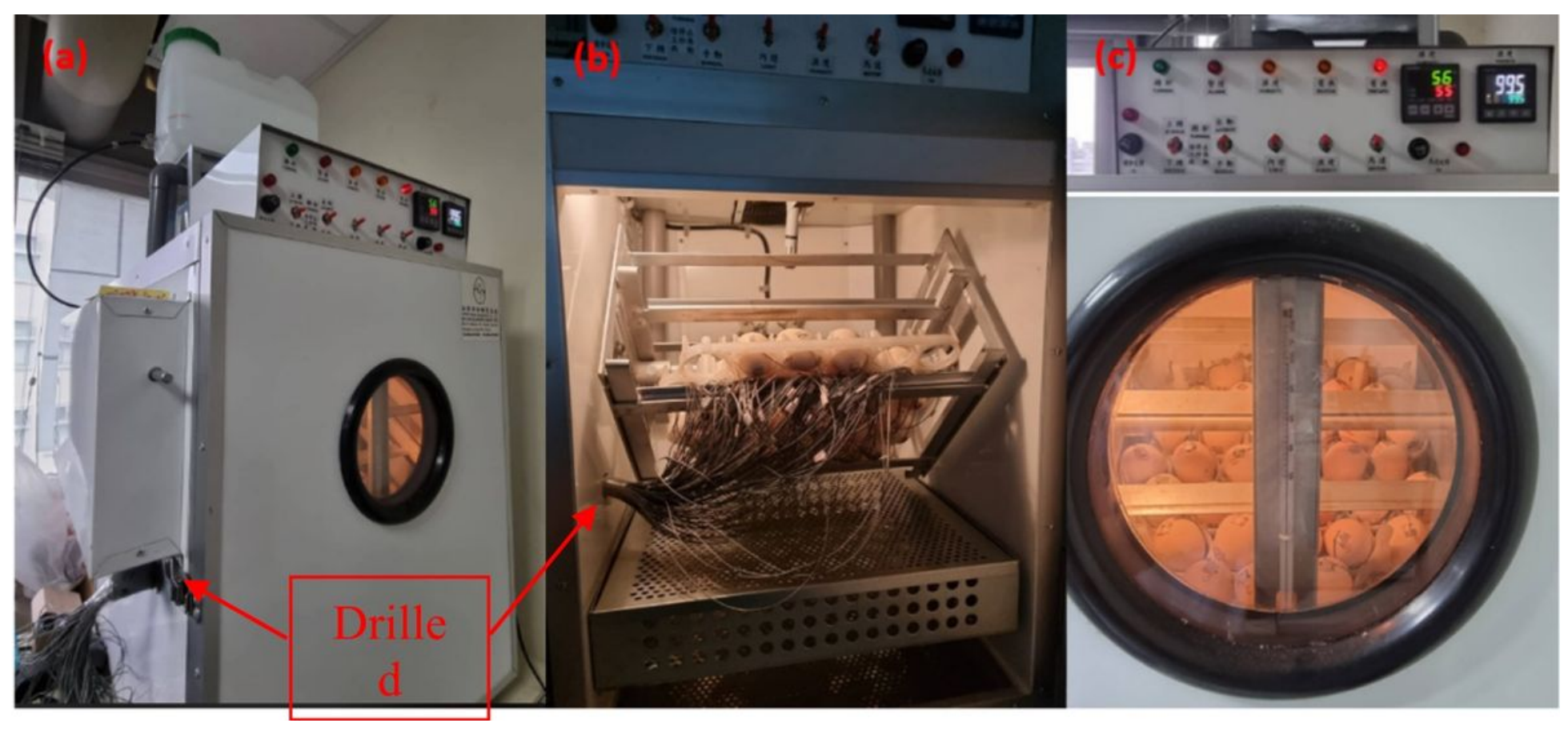

\section{Figure 6}

(a) The small size incubator used in this research (b) The electrode cables are tunneled outside through a small $20 \mathrm{~mm}$ diameter hole (c) the machine settings are kept steady at $55 \%$ humidity level, and temperature of $99.50 \mathrm{~F}$. 


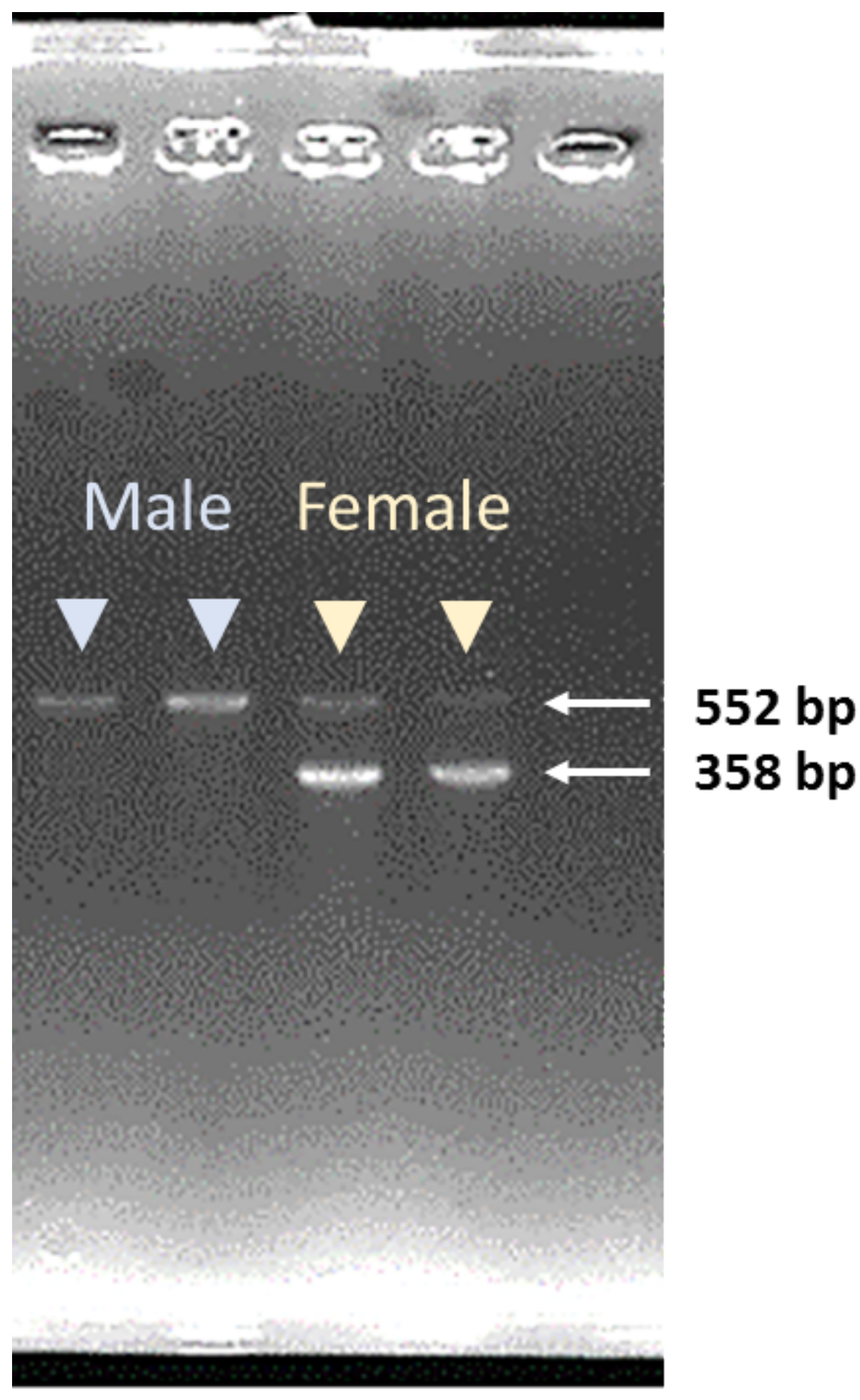

Figure 7

Sex identification for chick fetus using PCR. One single band at $552 \mathrm{bp}$ indicated a male fetus and two bands at $552 \mathrm{bp}$ and $358 \mathrm{bp}$ indicated a female fetus. 


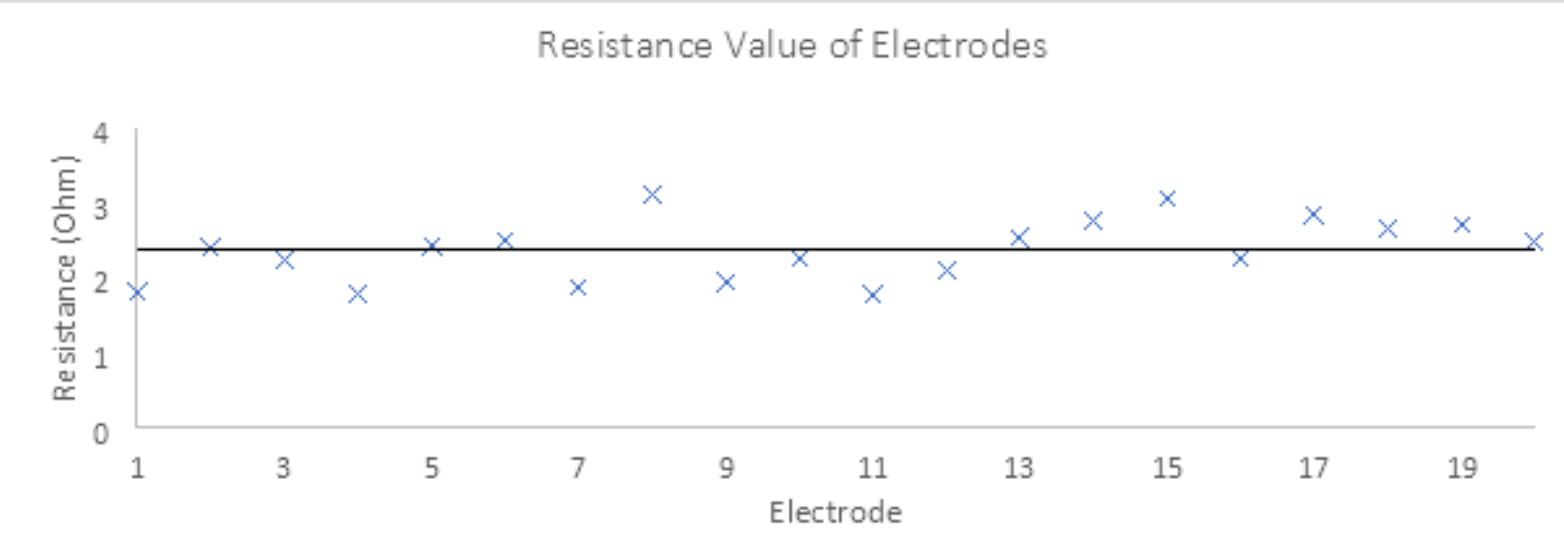

Figure 8

Electrode resistance validation 
[a]

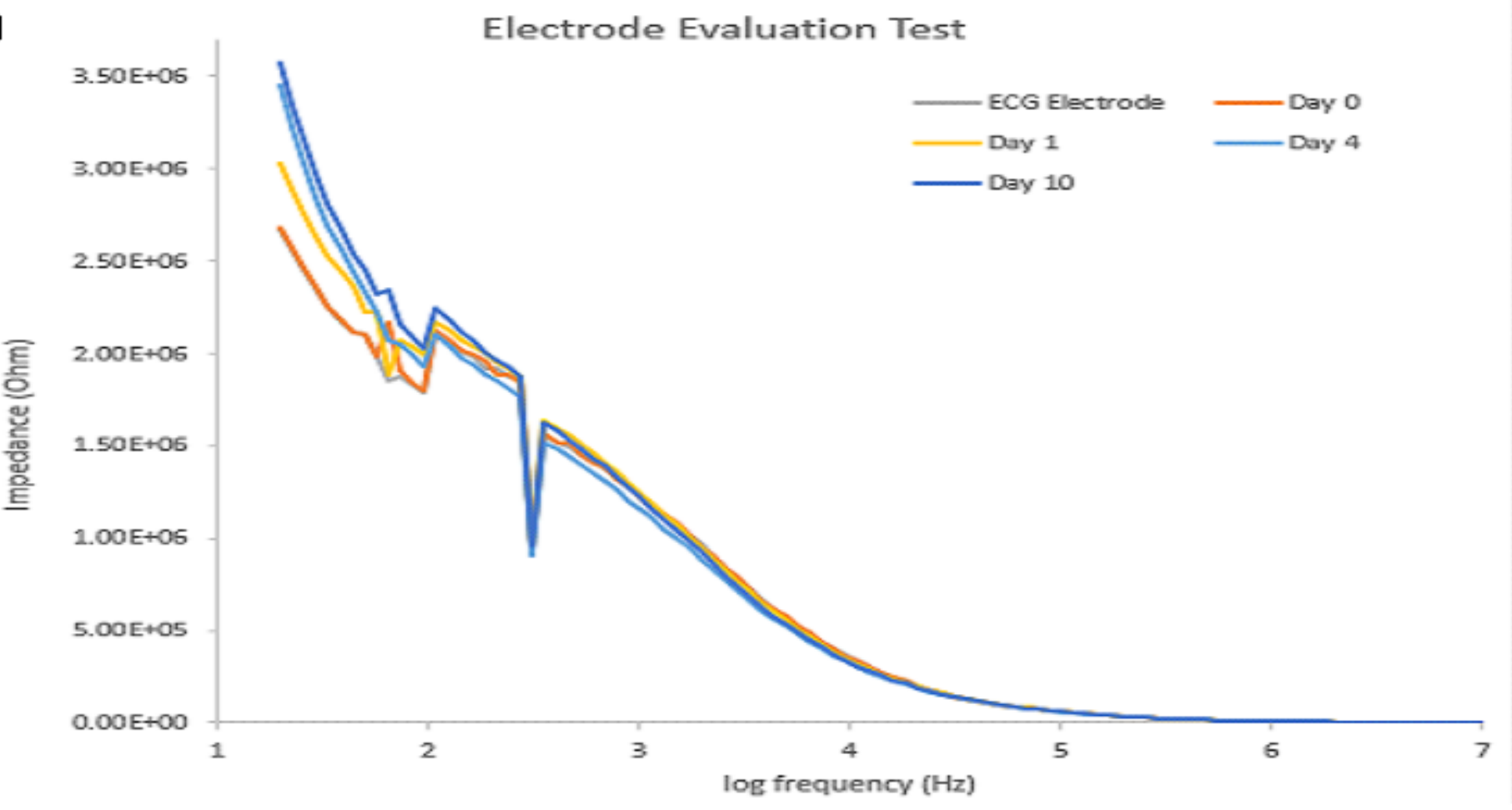

(b)

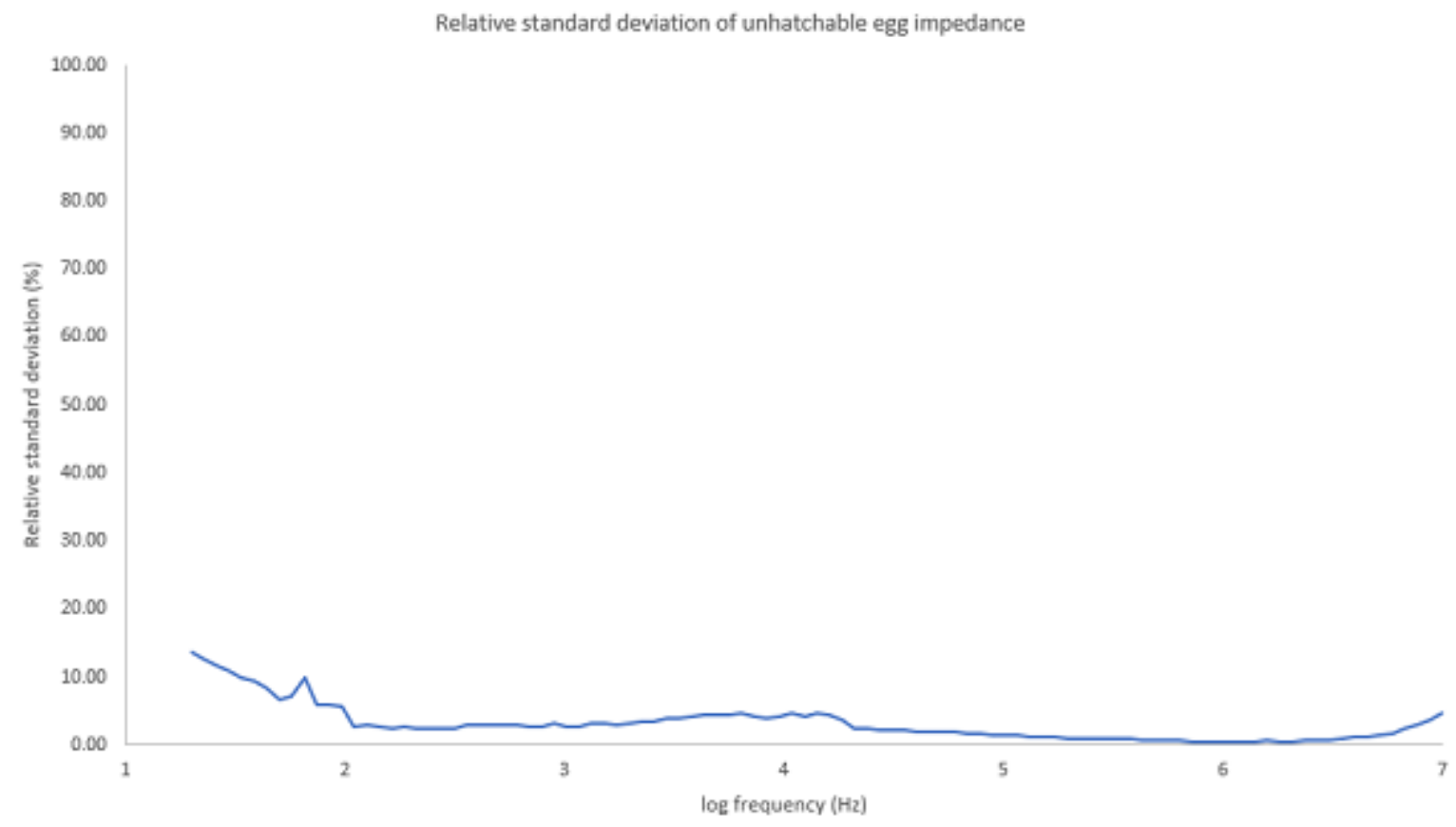

Figure 9

(a) Impedance data of an unhatchable egg at different days with (b) relative standard deviation 

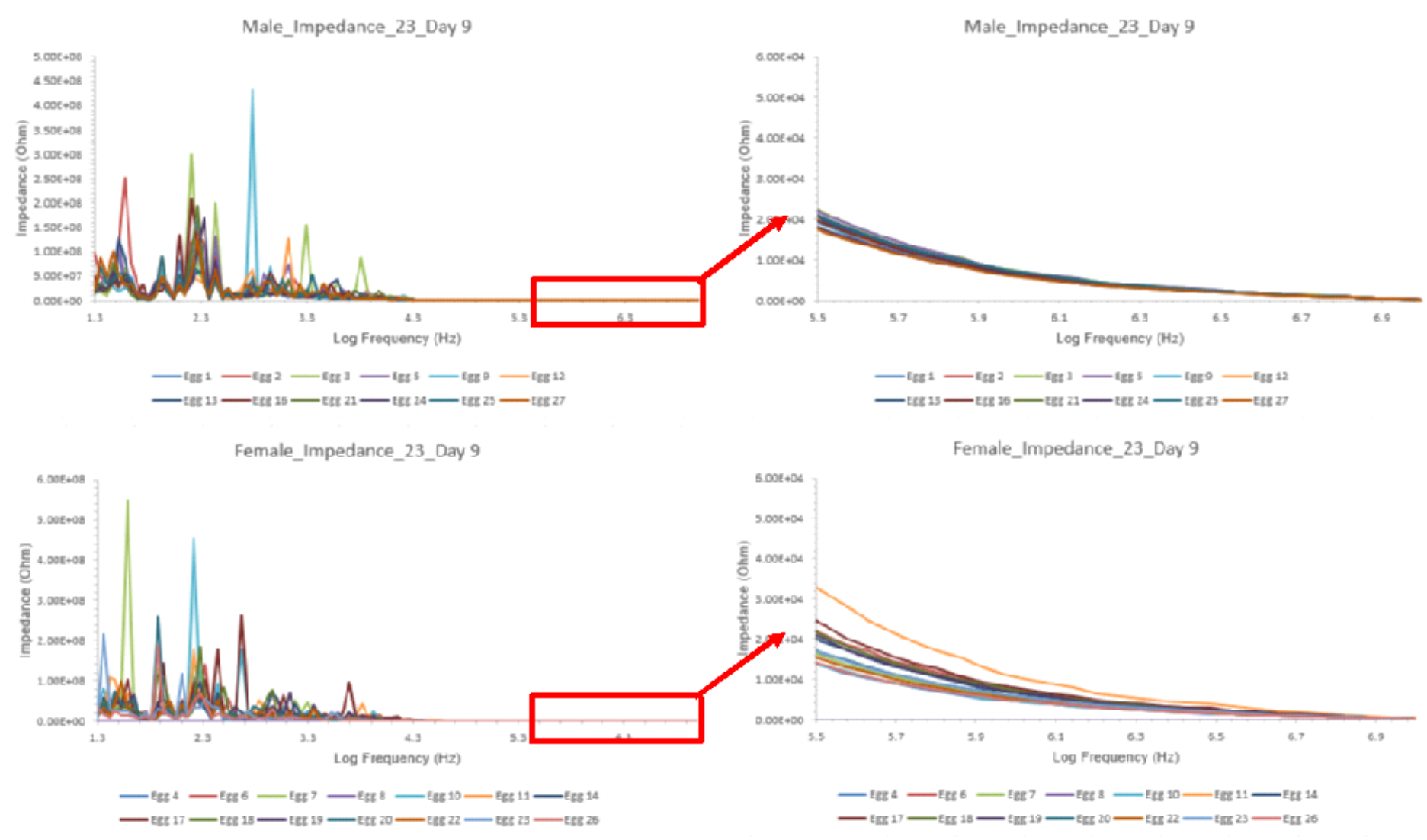

Figure 10

Impedance spectrum measurement of male and female eggs between electrodes at position 2-3 aon Day 9 


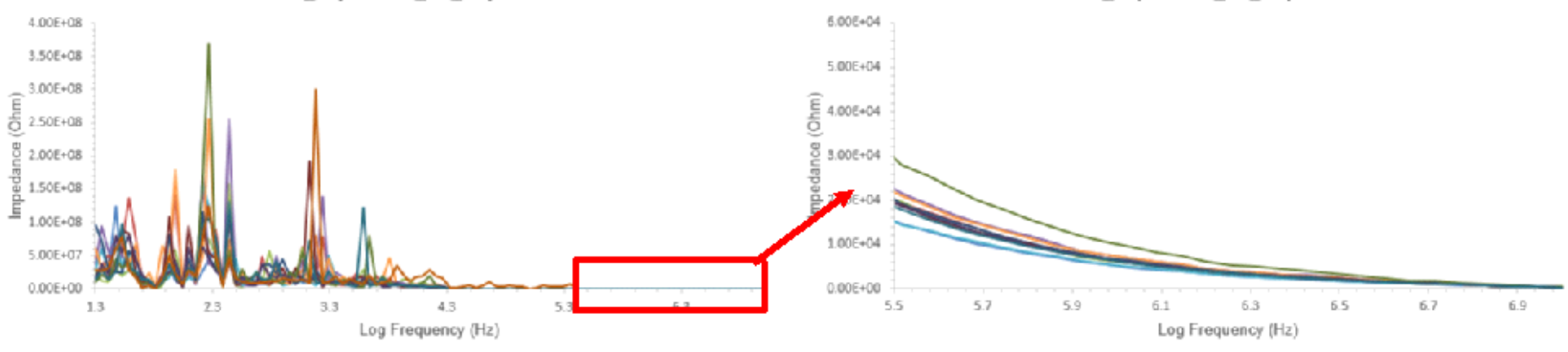

$$
\begin{gathered}
-\operatorname{Eet} 1-\operatorname{tge} 2-\operatorname{Ese} 3-\operatorname{Egs} 5-\operatorname{Ees} 9-\operatorname{Eeg} 12 \\
\text { Female_Impedance_24_Day } 9
\end{gathered}
$$

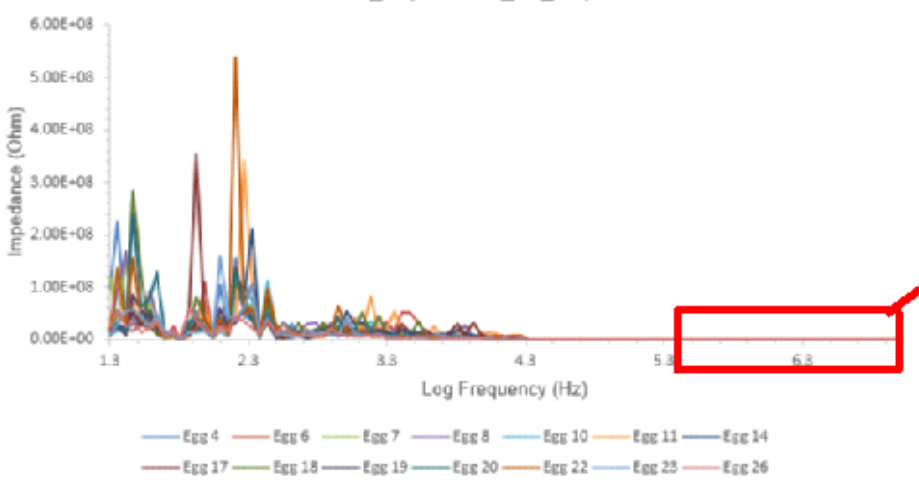

$$
\begin{gathered}
-\operatorname{Eet} 1-\operatorname{Esc} 2-\operatorname{Etg} 3-\operatorname{Ees} 5-\operatorname{Eet} 9-\operatorname{Esc} 12 \\
\text { Female_Impedance_24_Day } 9
\end{gathered}
$$

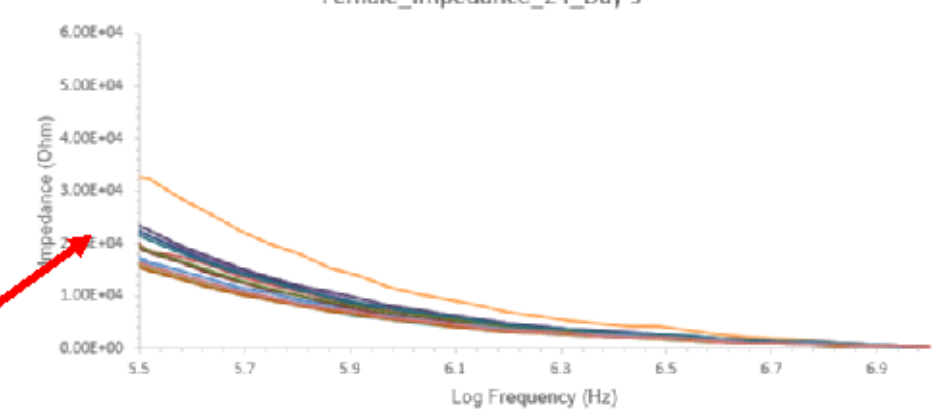

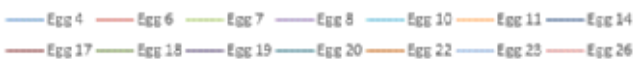

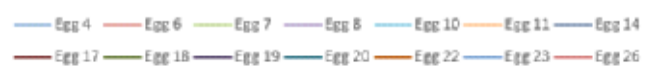

\section{Figure 11}

Impedance spectrum measurement of male and female eggs between electrodes at position 2-4 on Day 9 

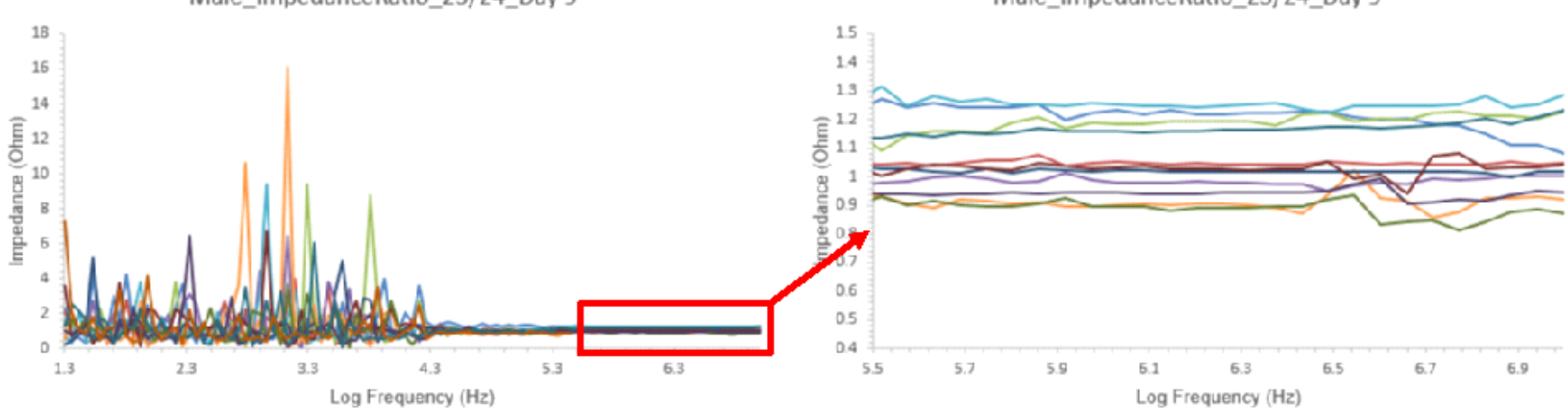

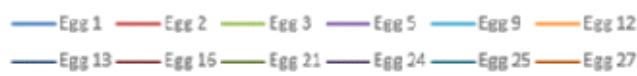

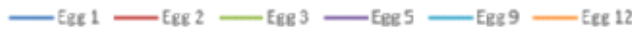

Female_ImpedanceRatio_23/24_Day 9

-Ege $13-\operatorname{Egg} 16-\operatorname{Egg} 21-\operatorname{Egg} 24-\operatorname{Egg} 25-\operatorname{Egg} 27$

Female_ImpedanceRatio_23/24_Day 9
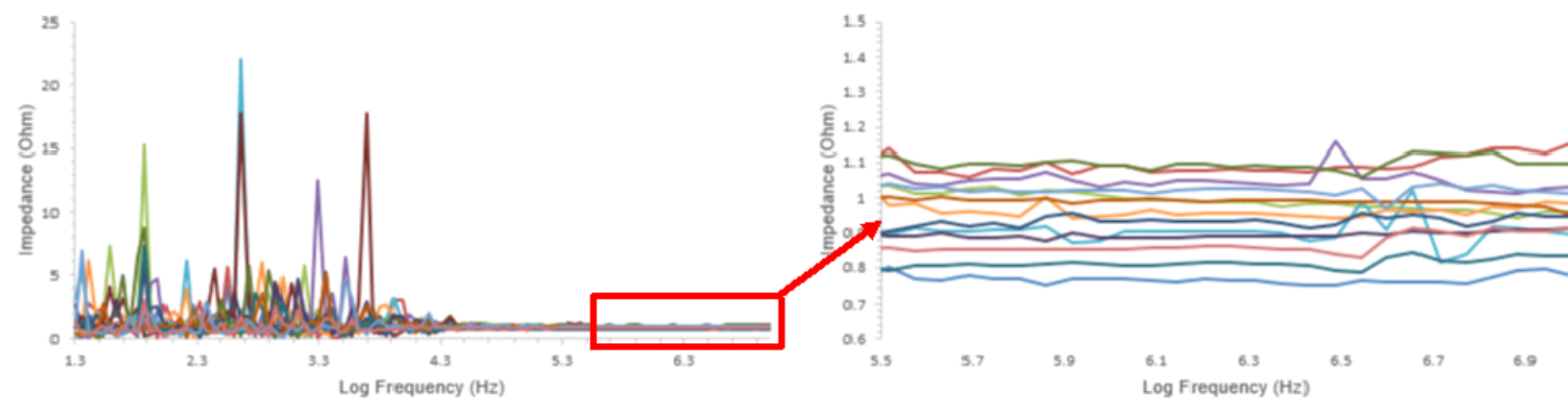

$-\operatorname{tgg} 4-\operatorname{tgg} 6-\operatorname{tgg} 7-\operatorname{tgg} 3-\operatorname{tgg} 10-\operatorname{tgg} 11-\operatorname{tgg} 14$

- $\operatorname{tgg} 4-\operatorname{tgg} 6-\operatorname{tgg} 7-\operatorname{tgg} 8-\operatorname{tgg} 10-\operatorname{Egg} 11-\operatorname{tgg} 14$

$-\operatorname{tgg} 17-\operatorname{tgg} 18-\operatorname{tgg} 19-\operatorname{tgg} 20-\operatorname{tgg} 22-\operatorname{tgg} 23-\operatorname{tgg} 26$

$-\operatorname{tgg} 17-\operatorname{tgg} 18-\operatorname{tgg} 19-\operatorname{tgg} 20-\operatorname{tgg} 22-\operatorname{tgg} 23-\operatorname{tgg} 26$

\section{Figure 12}

The self-normalized spectrum of Impedance of pair 2-3 divided by Impedance of pair 2-4 Impedance Ratio 23/24_Day 9

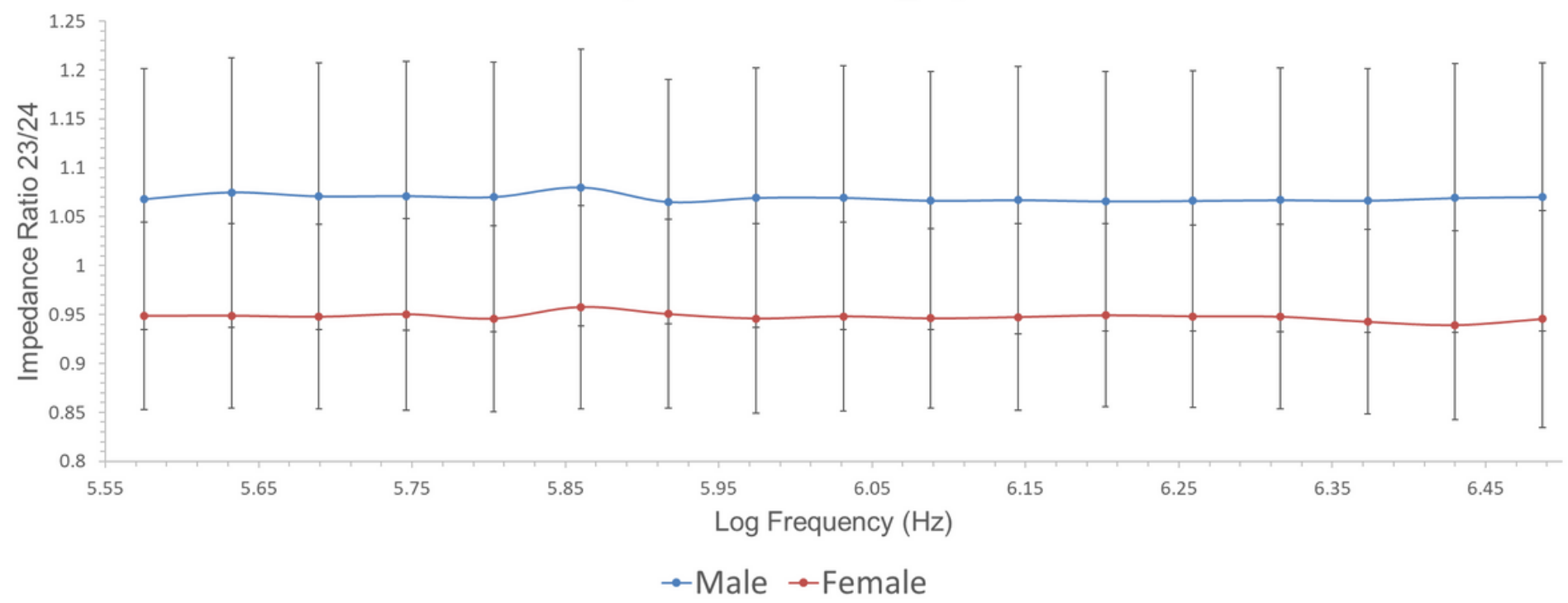

Figure 13 
Mean impedance ratio value of male and female egg in the optimum frequency range.

Impedance Ratio $23 / 24$ _ $376 \mathrm{kHz}$

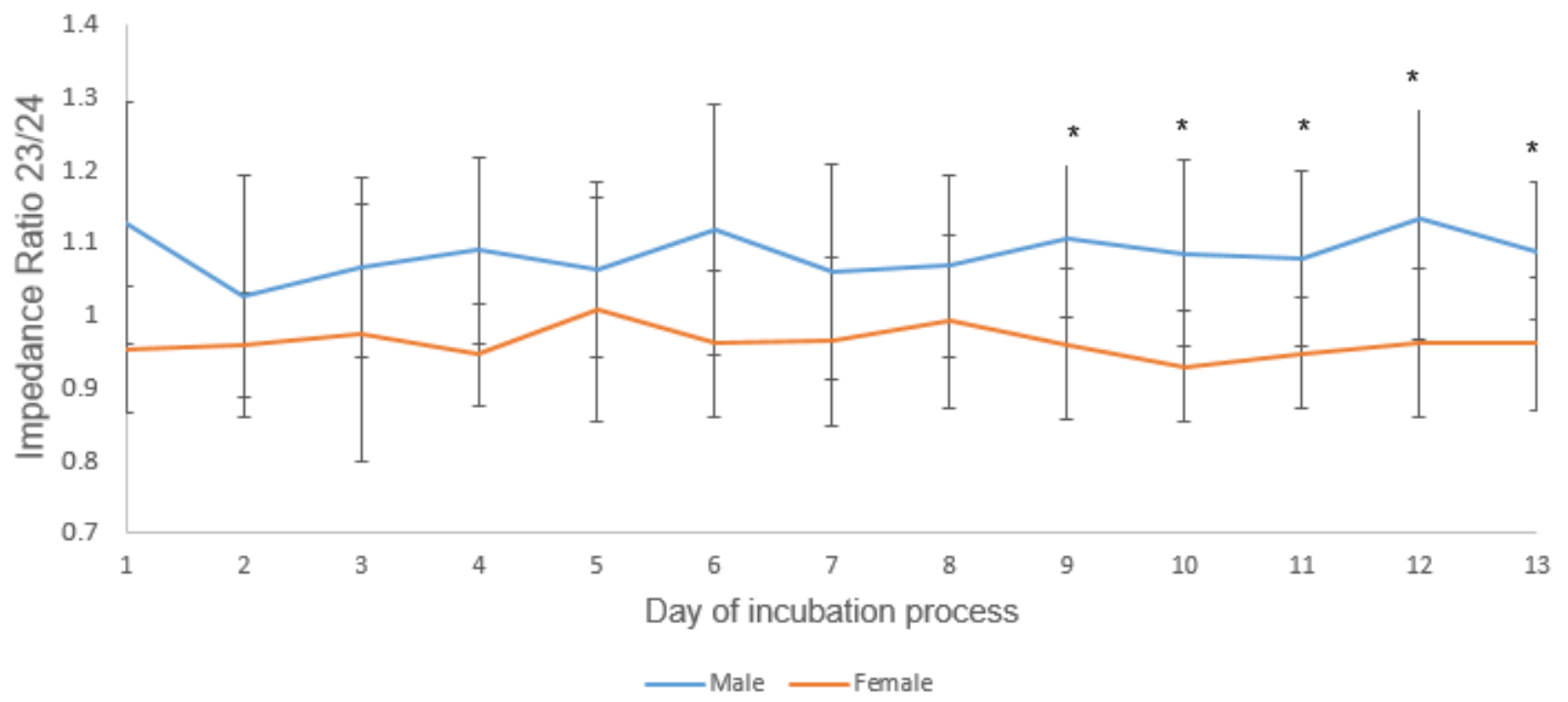

Figure 14

Mean impedance ratio of male and female eggs through out the 13 days of incubation measured at the frequency of $376 \mathrm{kHz}$. Remark: ${ }^{*} \mathrm{p}$ value $<0.05$ 